\title{
Correction: knowledge of HIV and factors associated with attitudes towards HIV among final-year medical students at Hanoi medical university in Vietnam
}

Michael Platten ${ }^{1}$, Ha N Pham ${ }^{1,2}$, Huy V Nguyen ${ }^{3^{*}}$, Nhu T Nguyen ${ }^{4}$ and Giang M Le ${ }^{5}$

\section{Correction}

After the publication of this work [1], we became aware that two authors had not appeared in the authorship list. This is because during the article write-up and review process, we forgot to include some other authors who at the beginning stage of the research also contributed greatly to the conceptualization and design of the research. This caused the incomplete authorship in the article.

The updated author list is: Michael Platten, Ha N Pham, Huy V Nguyen, Nhu T Nguyen \& Giang M Le.

The updated authors' contributions are: NTN, LMG and $\mathrm{NVH}$ conceptualized and designed the study. MP wrote the manuscript. $\mathrm{NVH}$ and $\mathrm{PNH}$ both contributed to data analysis and writing the manuscript. NTN and LMG applied for ethical approval for this study. All authors read, reviewed and approved the final manuscript.

\footnotetext{
Author details

${ }^{1}$ Department of Public Health Sciences, Karolinska Institutet, Stockholm, Sweden. ${ }^{2}$ World Health Organization, Hanoi, Vietnam. ${ }^{3}$ Department of Health Management and Organization, Institute for Preventive Medicine and Public Health, Hanoi Medical University, Hanoi, Vietnam. ${ }^{4}$ Family Health International 360, Hanoi, Vietnam. ${ }^{5}$ Department of Epidemiology, Institute for Preventive Medicine and Public Health, Hanoi Medical University, Hanoi, Vietnam
}

Received: 29 May 2014 Accepted: 29 May 2014

Published: 9 June 2014

\section{Reference}

1. Platten M, Pham HN, Nguyen HV, Nguyen NT, Le GM: Knowledge of HIV and factors associated with attitudes towards HIV among final-year medical students at Hanoi medical university in Vietnam. BMC Public Health 2014, 14:265.

\footnotetext{
* Correspondence: nvanhuy@yahoo.com

${ }^{3}$ Department of Health Management and Organization, Institute for Preventive Medicine and Public Health, Hanoi Medical University, Hanoi, Vietnam

Full list of author information is available at the end of the article
}

doi:10.1186/1471-2458-14-576

Cite this article as: Platten et al:: Correction: knowledge of HIV and factors associated with attitudes towards HIV among final-year medical students at Hanoi medical university in Vietnam. BMC Public Health 2014 14:576. 